\title{
INVESTIGATION OF THE GROWTH MECHANISMS OF a-CHx COATINGS DEPOSITED BY PULSED REACTIVE MAGNETRON SPUTTERING
}

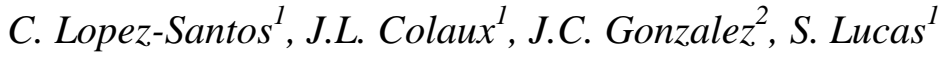 \\ 1) Namur Research Institute for Life Sciences (NARILIS), Research Centre for the \\ Physics of Matter and Radiation (PMR-LARN) University of Namur- FUNDP Rue de \\ Bruxelles, 61, B-5000 Namur, Belgium \\ 2) Institute of Materials Science of Seville (CSIC - University of Seville). Américo \\ Vespucio 49, E-41092 Seville, Spain
}

\begin{abstract}
The study of the growth mechanisms of amorphous hydrogenated carbon coatings (a$\mathrm{CH}_{\mathrm{x}}$ ) deposited by reactive pulsed magnetron discharge in $\mathrm{Ar}+\mathrm{C}_{2} \mathrm{H}_{2}, \mathrm{Ar}+\mathrm{H}_{2}$ and Ar $+\mathrm{C}_{2} \mathrm{H}_{2}+\mathrm{H}_{2}$ low pressure atmospheres is presented in this work. Hydrogen-containing species of the reactant gas affect the microstructure and surface properties of the a- $\mathrm{CH}_{\mathrm{x}}$ thin films. The dynamic scaling theory has been used to relate the main reactive species involved in the deposition process to the growth mechanisms of the thin film by means of the analysis of the roughness evolution. Anomalous scaling effects have been observed in the smooth $\mathrm{a}-\mathrm{CH}_{\mathrm{x}}$ coatings. Dynamic scaling exponents $\alpha, \beta$ and $\mathrm{z}$ indicate a general growth controlled by surface diffusion mechanisms. Hydrogen species have an influence on the lateral growth of the a- $\mathrm{CH}_{\mathrm{x}}$ coatings and are involved in the development of a polymeric-like structure. Meanwhile, hydrocarbon species promote the generation of
\end{abstract}


higher aggregates that increases the roughness of a more $\mathrm{sp}^{2}$ clustering structure of the aa-CH $\mathrm{CH}_{\mathrm{x}}$ coating.

\section{Introduction}

Amorphous hydrogenated carbon coatings $\left(\mathrm{a}-\mathrm{C}: \mathrm{H}_{\mathrm{x}}\right)$ have a notable impact in a wide range of industrial applications due to the combination of special properties such as the hardness, high wear resistance, chemical inertness and low friction coefficient, among others [1]. The special structure of the a- $\mathrm{CH}_{\mathrm{x}}$ coatings is composed of carbon, bonded in $\mathrm{sp}^{2}$ and $\mathrm{sp}^{3}$ electronic configurations, and hydrogen. This microstructure determines their versatility [2] to be used like protective coating of optical and magnetic storage devices [3], mechanical components [4] or biomedical instruments [5]. The development of a suitable deposition method to produce a- $\mathrm{CH}_{\mathrm{x}}$ coatings directed to a specific application has been one of the main current goals of investigation. Among the well established systems of a- $\mathrm{CH}_{\mathrm{x}}$ deposition, we can find plasma-enhanced chemical vapour deposition [6], ion beam deposition [7], pulsed laser ablation [8] or magnetron sputtering [9]. Deposition of a-C: $\mathrm{H}_{\mathrm{x}}$ coatings by magnetron discharge have been studied because such technology is suitable for many industrial applications [9-11]. An improvement of the process can be achieved through a pulsed configuration and the use of graphite targets with an hydrocarbon gas precursor $[9,12]$. However, the effect of the predominant growth processes on the obtained microstructure of the $\mathrm{a}-\mathrm{CH}_{\mathrm{x}}$ material, in a basic pulsed magnetron sputtering deposition, has not been completely understood. Experimental conditions have a strong influence on the reaction mechanisms during the growth of the a- $\mathrm{CH}_{\mathrm{x}}$ material and, subsequently, on its microstructure. As example, smooth a- $\mathrm{CH}_{\mathrm{x}}$ films 
has been observed at low pressure work conditions, whereas the development of rougher microstructures were possible by increasing the pressure [13]. Other experimental parameters can provide different ratios of $\mathrm{sp}^{2}$ and $\mathrm{sp}^{3}$ carbon bonds and hydrogen contents [14-18].

Control of the a- $\mathrm{CH}_{\mathrm{x}}$ growth mechanisms at low plasma pressure becomes a key goal of study depending on the final application. In order to understand the physical-chemical reactions taking place during the growth of the a- $\mathrm{CH}_{\mathrm{x}}$ material, several models have been proposed [1, 19-21]. However, the growth of a-CHx films is a complicated nonequilibrium set of processes. Most of them happen on the surface and in the subsurface layers during simultaneous deposition of carbon species and ion bombardment. This general hypothesis is based on the preferential displacement of $\mathrm{sp}^{2}$ bonded atoms, the densification by recoil implantation and relaxation, and the subplantation of atoms and stress relaxation. Therefore, the influence of each mechanism can be affected by the experimental parameters of deposition, such as the ion flux or the substrate temperature. Thus, growth studies based on optical spectroscopy [1, 22], spectroscopy ellipsometry [20], mass spectrometry $[23,24]$ and energetic considerations about the impinging species [25] can be found. Other proposed models come from the analysis of the a- $\mathrm{CH}_{x}$ coating properties. The development of a surface morphology can be affected by the competition between surface roughening and smoothing mechanisms during film growth, what can be explained through dynamic surface growth models [26]. Dynamic scaling hypothesis assumes that the growth of a self-affine surface does not scale the same way in the vertical direction as the lateral direction. A self-affine surface seems to have both short range space scaling and long-range time scaling. By measuring the roughness 
evolution through the scaling coefficients ( $\alpha$ roughness and $\beta$ growth exponents), it is possible to deduce the main growth mechanisms, such as a "ballistic deposition" (direct chemisorption of a growth precursor upon impact) or a "surface diffusion mediated deposition" (chemisorption, which is mediated by a preceding surface diffusion step) [21].

Dynamic scaling hypothesis has been recently applied in the smooth a-C: $\mathrm{H}_{\mathrm{x}}$ films formation [20, 21, 27-30]. As example, Zhu et al. [27] have proposed a set of processes responsible for the formation of amorphous diamond-like carbon under ion beam growth conditions: a dense diamond-like phase generation takes place during the slowing-down process of ion collision simultaneously to some relaxation mechanisms, such as the asymmetric displacement of $\mathrm{sp}^{2} / \mathrm{sp}^{3}$ carbon atoms, thermally activated density, and stress relaxation processes. In the case of a- $\mathrm{CH}_{\mathrm{x}}$ coatings grown by sputtering techniques, there are only a few suggested growth models. Logothetidis et al. [20] have described the kinetics of carbon sputter deposition in function of the effect of the ion energy bombardment. Whereas, Pei et al. [29] have studied the growth of a similar material like TiC/a-C nanocomposite coatings deposited by pulsed DC magnetron sputtering with a biased substrate configuration. The common conclusion relates the growth of smooth a$\mathrm{C}: \mathrm{H}_{\mathrm{x}}$ coatings to the existence of an ion-induced downhill current of material, providing a local growth rate dependence on the local surface curvature [28, 30-32]. However, when the growth of a-C: $\mathrm{H}_{\mathrm{x}}$ coatings occurs without the presence of ion bombarding, other processes must be involved. This is the case of smooth a-C: $\mathrm{H}_{\mathrm{x}}$ thin films deposited by magnetron sputtering without ion beam assistance or a biased substrate. For this purpose, an exhaustive study of the growth of a-C: $\mathrm{H}_{\mathrm{x}}$ coatings through the application of the 
dynamic scaling theory is presented in this work. From the values of the experimental scaling exponents, theoretical and numerical simulations of nonequilibrium process deposition have been proposed. The Edwards-Wilkinson model is based on the random deposition with surface relaxation (obtaining $\alpha=0$ and $\beta=0$ ) [33], while the KardarParisi-Zhang model [34] includes the relaxation of the interface by a surface tension, and the random fluctuation in the incoming flux (with $\alpha=0.5$ and $\beta=0.33$ ). Drotar et al. [35] established a shadowing model through Monte Carlo simulations (resulting a roughening growth exponent $\beta=1$ ) and Das Sarma and Tamborenea [36] model related the relaxation of the deposited atoms with the ratio between the deposition rate to the hopping rate. Taking them into account, the aim of the present work pursues to contribute to the interpretation of the physical-chemical mechanisms affecting the final microstructure of the a- $\mathrm{CH}_{\mathrm{x}}$ coatings, deposited by magnetron sputtering, according to the more influential hydrocarbon species. The identification of these activated radicals, as well as the surface characterization of the a- $\mathrm{CH}_{\mathrm{x}}$ thin films by means of the analysis of the chemical composition, microstructure and topography are used to support the present study.

\section{Experimental}

\subsection{Deposition system}

Deposition reactor was a vacuum cylinder chamber of stainless steel, assisted by an unipolar pulsed magnetron sputtering source with two confocal 2" graphite targets ( $99.9 \%$ purity). Graphite targets are oriented at $45^{\circ}$ respect to the surface sample normal

direction. The residual vacuum was below $10^{-4} \mathrm{~Pa}$. Several mixtures of gasses were used: $20 \mathrm{sccm}$ of argon (99.9\% purity) and $4 \mathrm{sccm}$ of acetylene (99.0\% purity), $\left(\mathrm{Ar}+\mathrm{C}_{2} \mathrm{H}_{2}\right.$ 
mixture), $20 \mathrm{sccm}$ of argon and $4 \mathrm{sccm}$ of hydrogen (99.0\% purity), (Ar+ $\mathrm{H}_{2}$ mixture) and $20 \mathrm{sccm}$ of argon with acetylene and hydrogen, both $4 \mathrm{sccm}\left(\mathrm{Ar}+\mathrm{C}_{2} \mathrm{H}_{2}+\mathrm{H}_{2}\right.$ mixture). A differentially pumped RC RGA Analyzer HAL7 quadrupole mass spectrometer (Hiden PSM) was employed to characterize the plasma radicals and sputtered species impinging on the substrate during the magnetron sputtering deposition. The study was carried out in residual gas analysis mode, where the ions formed are focused to the quadrupole mass filter and classified by their mass / charge ratio $(\mathrm{m} / \mathrm{z})$. Pressure during the deposition was maintained between $2.9-4.4 \times 10^{-1} \mathrm{~Pa}$, depending on the flux of reactive gasses. Both targets were connected in parallel on the same pulsed power supply wich delivered a mean power of $250 \mathrm{~W}$ with a pulse time-on and a duty cycle set to $50 \mu$ s and $50 \%$, respectively. The used substrates were glass well-cleaned by two ultrasound baths in water and ethanol.

\section{2 a-CHx $\mathrm{CH}_{x}$ coatings characterization}

Composition depth profiles were obtained by ion beam analysis through the combination of Elastic Recoil Detection Analysis (ERDA) and Rutherford Backscattering Spectroscopy (RBS). An impinging beam of ${ }^{4} \mathrm{He}^{+}$at $2.4 \mathrm{MeV}$ was used and the sample was tilted at an angle of $70^{\circ}$ between the normal surface direction and the incident beam direction. The detectors were placed at $135^{\circ}$ (RBS) and $30^{\circ}$ (ERDA). The composition depth profiles of the a-C: $\mathrm{H}_{x}$ films were obtained by fitting the RBS and ERDA spectra using SIMTarget [37] and SIMNRA [38] codes.

Raman spectroscopy was performed by a RH800 Horiba Jovin-Yvon $\mu$-Raman spectrometer with the IK Series He-Cd laser $(\lambda=325 \mathrm{~nm})$. A grating with $1800 \mathrm{~g} \cdot \mathrm{mm}^{-1}$, a 
CCD detector cooling by air and an Olympus BX-41 metallographic microscope attached to the spectrometer were employed. Raman spectra were collected in backscattering configuration, using a silicon wafer for the calibration.

Thickness of the a- $\mathrm{CH}_{\mathrm{x}}$ layer was estimated with a stylus profilometer from Veeco Instruments (Surface Profile Measuring System Dektak). Knowing the thickness and the atomic density provided by nuclear techniques, the density was estimated.

Surface topography and roughness were analyzed by a Multimode 8 Atomic Force Microscopy AFM (Veeco diNanoScope V). AFM images were acquired with Si tips of $350-380 \mathrm{kHz}$ of resonant frequency and $8-20 \mathrm{~N} / \mathrm{m}$ of spring constant working in tapping mode. AFM analysis was performed with the WSxM free available software from Nanotec [39].

\subsection{Dynamic scaling theory}

Growth processes for the evolution of amorphous hydrogenated carbon films can be studied trough the dynamic scaling theory. According to this model, for a self-affine surface, the roughness $\mathrm{R}(\mathrm{L}, \mathrm{t})$ can be scaled as a function of both the scale of measurement (L) and deposition time (t), following the Family-Vicsec relation [40, 41]:

$$
R(L, t)=L^{\alpha} f\left(t / L^{\alpha / \beta}\right)
$$

Here $\alpha$ and $\beta$ parameters are the roughness and growth exponents, respectively, and $f(u)$ is a function with $\mathrm{f}(\mathrm{u})_{\mathrm{u}<<1} \sim \mathrm{u}^{\beta}$ and $\mathrm{f}(\mathrm{u})_{\mathrm{u}>>1} \sim$ Const. Asymptotic behavior of the surface roughness scales as $R(L, t) \sim t^{\beta}$ if $t<<L^{\alpha / \beta}$, whereas is represented by $R(L, t) \sim L^{\alpha}$ when $t \gg L^{\alpha / \beta}$. Scaling exponents can be estimated from the dimensional analysis by AFM measurements, using the evolution of the roughness with time or with the height-height 
correlation function $\mathrm{HCF}(\mathrm{L})$ [41]. $\mathrm{HCF}(\mathrm{L})$ is an averaged distribution of heights depending on the lateral distance of the scanned surface. From this function it is possible to deduce the lateral correlation length $\xi$, that informs about the typical lateral length below which surface heights are statistically correlated and is described as $\xi \sim \mathrm{t}^{1 / z}$. This new exponent is called the coarsening exponent and usually obeys the relation $z=\alpha / \beta$ [42]. Also it is useful to obtain the power spectral density $\operatorname{PSD}(\mathrm{k})$ by means of the Fourier transform of the topography. These functions present the following asymptotic tendencies $[41,42]$ :

$\mathrm{HCF}(\mathrm{L}) \square\left\{\begin{array}{l}\mathrm{L}^{2 \alpha}(\mathrm{L}<<) \\ \operatorname{const}(\mathrm{L}>>)\end{array}\right.$
$\mathrm{PSD}(\mathrm{k}) \square\left\{\begin{array}{l}\operatorname{const}(\mathrm{k}<<) \\ \mathrm{k}^{-(2 \alpha+\mathrm{d})}(\mathrm{k}>>)\end{array}\right.$

where $d$ is the dimension of estimation for the $\operatorname{PSD}(\mathrm{k})$. The presence of a maximum $(\lambda)$ on the $\operatorname{PSD}(\mathrm{k})$ indicates a wavelength selection on the surface, corresponding to the typical distance between mounds [40, 41].

\section{Results and discussion}

3.1 Influence of the different gas species and sputtered particles on the a-CHx coating chemical composition and structure

Mass spectrometry analysis provides the identification of the main activated species at the different experimental deposition conditions. Atomic species such as $\mathrm{Ar}$ and $\mathrm{H}$, molecules such as $\mathrm{H}_{2}, \mathrm{C}_{2}$ or $\mathrm{C}_{2} \mathrm{H}_{2}$ and hydrocarbon radicals type $\mathrm{CH}, \mathrm{C}_{2} \mathrm{H}$ and $\mathrm{CH}_{2}$ were the main species detected during the $\mathrm{a}-\mathrm{CH}_{\mathrm{x}}$ thin films formation. The presence of activated argon species facilitate the ignition of the graphite sputtering [23, 43], 
improving the dissociation of the $\mathrm{C}_{2} \mathrm{H}_{2}$ molecule and hydrogen-containing radicals production [22]. Argon species take also part in the etching processes causing the surface bond breaking, hydrogen displacement in the growing material and generation of dangling bonds at the surface. These processes are related to the development of a smooth surface morphology [44], what is reflected in the following section. When hydrogen was used in the gas mixture, atomic species appeared predominant in the deposition process, as observed in Fig. 1. Meanwhile, the $\mathrm{C}_{2} \mathrm{H}_{2}$ molecule and $\mathrm{CH}_{2}$ and $\mathrm{CH}$ radicals were the most abundant when acetylene was the precursor. According to De Vriendt et al. [24], the fragmentation of acetylene in the gas phase generates positive species such as $\mathrm{C}^{+}, \mathrm{C}_{2}^{+}$, and $\mathrm{C}_{\mathrm{x}} \mathrm{H}_{\mathrm{y}}^{+}$that promote the carbon sputtering and subsequently the film growth. With the $\mathrm{Ar}+\mathrm{C}_{2} \mathrm{H}_{2}+\mathrm{H}_{2}$ mixture, the $\mathrm{CH}_{2}$ radical and $\mathrm{C}_{2} \mathrm{H}_{2}$ molecule remained in a notable concentration, even though hydrogen species continued being majority. It should also be mentioned that residual species like $\mathrm{OH}$ radicals were detected even at low pressure values.

Deposition of a- $\mathrm{CH}_{\mathrm{x}}$ thin films by reactive pulsed magnetron sputtering with different hydrogen-containing precursors, at low pressure conditions, provided coatings with large incorporation of hydrogen in the microstructure, around $30 \%$ at., as it can be observed in Table 1. Quantification of the atomic concentration for the different chemical composition of the a- $\mathrm{CH}_{\mathrm{x}}$ deposited coatings was carried out by Nuclear Reactions Analysis. Fig. 2 shows the depth profiles of carbon, hydrogen and oxygen obtained for the deposition with the $\mathrm{Ar}+\mathrm{C}_{2} \mathrm{H}_{2}$ mixture, as example, indicating an uniform chemical indepth composition. In general, acetylene precursor seemed to slightly increase the hydrogen concentration in the a- $\mathrm{CH}_{\mathrm{x}}$ layers, accompanied by a higher deposition rate. 
Small concentration of oxygen was detected in all the samples, around 5\% at. Density of the grown a- $\mathrm{CH}_{\mathrm{x}}$ thin films resulted in low values around $1.1-1.6 \mathrm{~g} \mathrm{~cm}^{-3}$, compared to other ones obtained in the literature [45]. Sample grown from the $\mathrm{Ar}+\mathrm{H}_{2}$ precursor resulted in the densest coating.

Study of the a- $\mathrm{CH}_{\mathrm{x}}$ structure induced by the magnetron sputtering deposition was performed by Raman analysis, as shown in Fig 3. Visible Raman spectra show the typical wide signal of a-CHe materials with the overlapping $\mathrm{G}$ and $\mathrm{D}$ peaks around $1540 \mathrm{~cm}^{-1}$ and $1360 \mathrm{~cm}^{-1}$, respectively. We can observe different shifts in the $\mathrm{G}$ peak position in function of the used hydrogen-containing precursors on Fig. 3. Hydrogen presence in the reactive mixture of gasses tended to move the $\mathrm{G}$ peak towards a higher position, whereas the $\mathrm{G}$ band corresponding to the deposition with the acetylene precursor was located at the lowest position. The appearance of the D peak in the Raman spectra indicates a large proportion of $\mathrm{sp}^{2}$ bonds in an aromatic ring arrangement. An additional wide band around $1150 \mathrm{~cm}^{-1}$ ( $\mathrm{D}^{*}$ band) is probably responsible for the increase of the background at this region. $\mathrm{D}^{*}$ band is related to the formation of transpolyacetylene phases due to the high hydrogen incorporation in the a-C: $\mathrm{H}_{\mathrm{x}}$ coatings [46-48]. Thin film grown from the mixture with acetylene and hydrogen presented a $\mathrm{I}^{\mathrm{D}} / \mathrm{I}^{\mathrm{G}}$ ratio value of 1.08 , slightly higher than the other samples $(\sim 0.87)$, indicating a lower $\mathrm{sp}^{3}$ content [48]. A tendency to increase the $\mathrm{I}^{\mathrm{D}} / \mathrm{I}^{\mathrm{G}}$ ratio with the concentration of hydrogen has been observed previously in DLC films deposited by PECVD [49].

Despite the fact that the found differences in the Raman analysis were small, the $\mathrm{I}^{\mathrm{D}} / \mathrm{I}^{\mathrm{G}}$ ratio and the $\mathrm{G}$ peak position values could indicate that the $\mathrm{Ar}+\mathrm{H}_{2}$ mixture generated a slightly higher disorder on the $\mathrm{sp}^{2}$ configuration than when acetylene was the precursor 
[46-48]. When the mixture of $\mathrm{Ar}+\mathrm{H}_{2}$ is used, hydrogen species (atom and molecule) are the most influential, specially because atomic hydrogen can create chemisorption sites (dangling bonds) $[16,23]$. Low energy of the impinging atoms provides a low growth rate that can increase the surface mobility of film-forming fragments and, consequently, the density [43]. The low intensity of hydrocarbon radicals detected in these experimental deposition conditions suggests that the main channels of a- $\mathrm{CH}_{\mathrm{x}}$ growth material take place through carbon sticking to the surface [23] followed by direct atomic hydrogen addition [44]. These mechanisms favour the $\mathrm{sp}^{2}$ hybridization and generation of a crosslinked polymer-like structure [50], as the present Raman results confirmed. During the coating formation, the addition of hydrogen saturates the $\mathrm{C}=\mathrm{C}$ bonds mainly converting $\mathrm{sp}^{2}$ carbon sites into $\mathrm{sp}^{3}=\mathrm{CH}_{2}$ and $\mathrm{CH}$ sites [51]. However, some deposition processes can introduce $\mathrm{sp}^{2}$ clusters even in samples with high hydrogen content [6], as it seems to happen in these a- $\mathrm{CH}_{\mathrm{x}}$ coatings. According to [52], the hydrogen incorporation provides the conversion of $\mathrm{sp}^{2}$ sites from rings into chains. Therefore, a polymeric-like character of the a-CHx coating could be thought.

In the case of the a- $\mathrm{CH}_{\mathrm{x}}$ thin films deposited from the mixture with acetylene, hydrocarbon radicals become more influential during the material growth. At these low pressure conditions of pulsed magnetron sputtering deposition, the high presence of the molecule $\mathrm{C}_{2} \mathrm{H}_{2}$ and the $\mathrm{C}_{2} \mathrm{H}$ and $\mathrm{CH}$ radicals indicates a strong hydrogen abstraction and polymerization reactions [23]. This fact is in agreement with the present Raman analysis, deducing a general structure of $\mathrm{sp}^{2}$ clusters with a small contribution of transpolyacetylene inclusions. The introduction of hydrogen flux to the mixture tends to reduce the presence of $\mathrm{CH}$ and $\mathrm{C}_{2}$ species, favoring the hydrogen abstraction from $\mathrm{C}-\mathrm{H}$ 
bonds on the growing material and the stabilization of $\mathrm{sp}^{3}$ carbon bonds by a preferential etching of previously deposited $\mathrm{sp}^{2}$ bonds [16]. The graphitization of the a- $\mathrm{CH}_{\mathrm{x}}$ films can be improved with the mixture $\mathrm{Ar}+\mathrm{C}_{2} \mathrm{H}_{2}+\mathrm{H}_{2}$, as the small increase of $\mathrm{G}$ peak position and the relatively high $\mathrm{I}^{\mathrm{D}} / \mathrm{I}^{\mathrm{G}}$ ratio indicated [18].

\subsection{Roughness analysis of the $a-\mathrm{CH}_{x}$ coatings}

In order to apply the dynamic scaling theory to get information about the effect of the hydrocarbon species on the growth mechanisms of the a- $\mathrm{CH}_{\mathrm{x}}$ coatings, AFM images for different deposition times have been acquired. Fig. 4 shows the topography of the a- $\mathrm{CH}_{x}$ coatings at two growth phases: at relatively low thickness $(60-70 \mathrm{~nm})$ and at larger thickness $(300-500 \mathrm{~nm})$ close to a saturation level of the roughness. There was a clear evolution of the a- $\mathrm{CH}_{\mathrm{x}}$ coatings topography: at first stages of growth, the development of small aggregates "grain-type" was observed. These structures presented averaged diameter around $60 \mathrm{~nm}$ for the sample deposited from the $\mathrm{Ar}+\mathrm{C}_{2} \mathrm{H}_{2}+\mathrm{H}_{2}$ precursor, whereas smaller aggregations of 40 and $20 \mathrm{~nm}$ arose for the depositions with $\mathrm{Ar}+\mathrm{C}_{2} \mathrm{H}_{2}$ and $\mathrm{Ar}+\mathrm{H}_{2}$ mixtures, respectively. Surface roughness values, obtained through the mean quadratic roughness coefficient $\mathrm{R}_{\mathrm{MS}}$ on Fig. 4, increased with the deposition time as well as the size of the "grain" features. Thick a- $\mathrm{CH}_{\mathrm{x}}$ coatings $(\sim 1 \mu \mathrm{m})$ deposited with the acetylene mixtures tended to develop similar microstructures to those introduced in previous works, named "cauliflower-like" [28, 29]. However, it was not possible to observe in the case of the sample grown with the $\mathrm{Ar}+\mathrm{H}_{2}$ mixture due to the low deposition rate, what would involve an excessive deposition time to reach a comparable thickness. 
Resulting smooth a- $\mathrm{CH}_{\mathrm{x}}$ topography is in agreement with previous roughness values of other deposited a- $\mathrm{CH}_{\mathrm{x}}$ thin films $[21,27,28,30]$. However, those works refer to the universality of the underlying smoothening mechanism according to the Edwards and Wilkinson model, under the main action of ions [32]. In the presence of hydrogencontaining species with absence of ion bombardment, hydrogen atom-assisted surface diffusion, instead of etching, is proposed to be the dominant smoothing mechanism [49]. It has been shown that, for DLC films produced by the deposition of carbon clusters, the mobility of surface atoms increases with the cluster incident energy [28]. Therefore, for low energies, atomic etching, shadowing and diffusion processes are proposed as surface smoothening mechanisms. The kinetics of the $\mathrm{a}-\mathrm{CH}_{\mathrm{x}}$ thin films formation is dependent on a number of factors including the intensity of $\mathrm{C}$ and $\mathrm{H}$ fluxes arriving at the substrate, the sticking coefficient/sticking probability of the particles, angular distribution of the fluxes reaching the surface, desorption of the atoms and mobility of ad-atoms on the growing surface. At the present experimental deposition conditions, low energetic impinging species become less mobile when arriving to the surface. This makes possible the hydrogen and carbon atoms bonding but also the formation of a large number of nuclei rather than the coalescing between neighbour nucleus [53]. This is the case of the a- $\mathrm{CH}_{x}$ coatings deposited from the hydrogen mixture. It is known that an enhanced renucleation of the growing film in the presence of $\mathrm{C}_{2}$ species, coming from the dissociation reactions of $\mathrm{C}_{2} \mathrm{H}_{2}$ and $\mathrm{C}_{2} \mathrm{H}$, increases the uniformity of the a- $\mathrm{CH}_{\mathrm{x}}$ surface grown from a mixture of $\mathrm{Ar}+\mathrm{C}_{2} \mathrm{H}_{2}$ [44]. Since the low working pressure may favour the mobility of arriving particles as well as an increase of different reactive species in the plasma, the mixture of gasses with acetylene seems to improve the grain growth by surface diffusion after 
nucleation on the growing surface. However, the introduction of hydrogen in the mixture with acetylene causes a small increase of the roughness, as it has been observed. In this case, the practically negligible degree of ionization and low energy of the species might cause a low penetration depth of the incoming particles and the formation of a rougher surface [18]

\subsection{Variation of the dynamic scale parameters of the a-CH $\mathrm{CH}_{x}$ coatings}

From the roughness temporal evolution slope, it is possible to deduce the $\beta$ growth exponent, such as indicated on Fig. 5a. Linear fitting on the region of low deposition times, out of the saturation regime, indicated similar growth exponent values of 0.13 for the a- $\mathrm{CH}_{\mathrm{x}}$ coatings grown with the two mixtures of gasses containing acetylene. This result could suggest the predominance role of $\mathrm{CH}$-type radicals on the growth, even if hydrogen species are abundant in the gas phase mixture. Sample deposited with the $\mathrm{Ar}+\mathrm{H}_{2}$ precursor showed a higher growth exponent of 0.21 . This difference between depositions with hydrogen and / or acetylene mixtures may indicate the importance of the main species inducing smoothing/roughening processes to modify the surface morphology, as it will be discussed in the last section.

The $\alpha$ roughness exponent can be obtained from the height-height correlation function $\mathrm{HCF}(\mathrm{L})$ or the power spectral density $\operatorname{PSD}(\mathrm{k})$, as shown in Fig. 6. Slopes at low k values were around -4 , being slightly higher for the sample deposited from the $\mathrm{Ar}+\mathrm{H}_{2}$ mixture. This result agrees with a prevalent surface diffusion process like responsible for the observed smooth topography [28]. A transition wave number $\mathrm{k}_{\mathrm{c}}=1 / \mathrm{L}_{\mathrm{c}}$ of the $\operatorname{PSD}(\mathrm{k})$ at the power law zone can be related to the typical distance between mounds originated on the 
a- $\mathrm{CH}_{\mathrm{x}}$ surface. At low time of deposition, this distance corresponds to the averaged film grain size in a compact surface $(\sim 60 \mathrm{~nm})$, while it is related to large aggregates structures with the development of a "cauliflower-like" topography $(\sim 300 \mathrm{~nm})$ for thicker samples. From the same growth stage in Fig. $6 a$, it could be deduced that the introduction of hydrogen to the mixture with acetylene tended to increase this typical distance from 125 $\mathrm{nm}$ to $200 \mathrm{~nm}$. Meanwhile, the sample deposited from the $\mathrm{Ar}+\mathrm{H}_{2}$ mixture presented an intermediate distance between mounds around $170 \mathrm{~nm}$. Its corresponding $\operatorname{PSD}(\mathrm{k})$ is below those of the a- $\mathrm{CH}_{\mathrm{x}}$ coatings grown with acetylene precursors that agrees with a lower surface roughness. So, it could be thought that the main hydrocarbon species provide an increase of the roughness. The joint effect of hydrogen and hydrocarbon species generated a higher roughness and a higher distance between mounds on the a$\mathrm{CH}_{\mathrm{x}}$ surface.

From the $\operatorname{HCF}(\mathrm{L})$ function shape, the increasing tendency at small $\mathrm{L}$ values is related to the kinetic roughening and the saturation at large $\mathrm{L}$ values suggests the absence of lateral correlation in the surface roughness. The height-height correlation function $\mathrm{HCF}(\mathrm{L})$ corresponding to the a- $\mathrm{CH}_{\mathrm{x}}$ coating deposited with the $\mathrm{Ar}+\mathrm{H}_{2}$ mixture also appears below the data of the samples grown from the acetylene precursor at large length scale. $\mathrm{HCF}(\mathrm{L})$ generally shifts upwards as the deposition thickness is increased, as it is possible to observe from the position of the maximum in Fig. 6b. Lateral correlation distance reached the value of $70 \mathrm{~nm}$ for the a- $\mathrm{CH}_{\mathrm{x}}$ deposited with the acetylene precursor, and was higher in the cases with the presence of hydrogen: $90 \mathrm{~nm}$ for the sample grown from the Ar+ $\mathrm{H}_{2}$ mixture and $140 \mathrm{~nm}$ in the coating grown from the $\mathrm{Ar}+\mathrm{C}_{2} \mathrm{H}_{2}+\mathrm{H}_{2}$ mixture. These results confirm a different local surface growth. 
The evolution of $\alpha$ during the different deposition processes is presented in Fig. 7. It should be considered a correction factor due to the size of the AFM tip and its convolution with the surface topography [54]. First information comes from the different exponents values deduced from both $\mathrm{HCF}(\mathrm{L})$ and $\operatorname{PSD}(\mathrm{k})$, as an evidence of the existence of local and global exponents, respectively. This is due to different growth behaviors at long and short length scales, known like anomalous scaling [42]. Lower global roughness exponent was found for the a- $\mathrm{CH}_{\mathrm{x}}$ layer deposited with the $\mathrm{Ar}+\mathrm{H}_{2}+\mathrm{C}_{2} \mathrm{H}_{2}$ mixture, whereas the deposition from the $\mathrm{Ar}+\mathrm{H}_{2}$ precursor involved a higher global $\alpha$ value. This tendency was inverted in the case of the local roughness exponent. Thus, main hydrogen species might increase the global roughness of the surface while the hydrocarbon radicals seemed to affect the local microstructure development of the grown a- $\mathrm{CH}_{\mathrm{x}}$ coating. The variation of $\alpha$ with the deposition time is also considered as a characteristic of the anomalous dynamic scaling, as shown Fig. 7. Larger variations of $\alpha$ with time deposition was observed in the a- $\mathrm{CH}_{\mathrm{x}}$ coating deposited with the $\mathrm{Ar}+\mathrm{H}_{2}$ mixture. According to Yanguas et al. [42], the change of $\alpha$ value with time indicates that the surface growth mechanisms do not preserve the fractal properties of the surface. Anomalous behavior is usually related to the shadowing processes constant in deposition geometries where species come from off-normal directions, as the present magnetron sputtering configuration. From these assumptions, the deposition of a- $\mathrm{CH}_{x}$ coatings from the mixture of $\mathrm{Ar}+\mathrm{H}_{2}$ should be more affected by shadowing effects than those thin films deposited with acetylene precursor. Anomalous dynamic scaling introduces a modification of the surface roughness evolution, dependent on the scale measurement (1) and expressed like $\mathrm{R}(1, \mathrm{t}) \sim \mathrm{t}^{\beta}$ if $\mathrm{t}\left\langle<\mathrm{l}^{\mathrm{z}}\right.$ and $\mathrm{R}(\mathrm{l}, \mathrm{t}) \sim \mathrm{t}^{\mathrm{K}} 1^{\alpha^{\prime}}$ if $\mathrm{t} \gg>\mathrm{l}^{\mathrm{z}}[41,55]$. Now, $\alpha^{\prime}$ coefficient 
is the local roughness exponent related to the scaling behaviour of a self-affine surface. It is noteworthy that, in these cases, the use of the $\alpha$ exponent deduced from the PSD of a mounded surface, not self-affine, is inappropriate [41]. Time dependence of the roughness is described by $\kappa=\beta-\alpha / z$.

It is known from the literature that low roughness of the a- $\mathrm{CH}_{\mathrm{x}}$ surface is associated to a low $\alpha$ and $\beta$ values $[28,30]$, due to a smoothening phenomena according to the Edwards and Wilkinson (EW) model [33]. EW model is based in a random deposition with surface relaxation, making reference to evaporation/condensation processes since those regions with local positive surface curvatures (depressions) grow faster than those with local negative surface curvatures (protrusions). In this case, roughness must be scaled like $\sim(\log t)^{0.5}$ for short times, and $\sim(\log 1)^{0.5}$ for long times. As example, linear representation shown in Fig. $5 b$ confirms the tendency to the EW model for the deposition time before saturation, as it was previously proposed by Buijnsters et al [28]. Rougher surfaces have been obtained with acetylene in the mixture of reactive gasses, due to the random arrival of relatively low energetic radicals, preferentially at the surface protrusions rather than at the valleys. This fact is typical from a shadowing effect, what gives preference to the growth in the vertical direction. However, since $\alpha$ and $\beta$ exponents have not been close to null like EW model predicted, other deposition mechanisms take place simultaneously. Low $\alpha$ values obtained for the a- $\mathrm{CH}_{\mathrm{x}}$ coatings deposited from the $\mathrm{Ar}+\mathrm{C}_{2} \mathrm{H}_{2}$ and $\mathrm{Ar}+\mathrm{H}_{2}$ mixtures are close to those corresponding to the nonlinear Kardar-Parisi-Zhang (KPZ) model [41]. According to this approximation, main growth processes are stabilization mechanisms such as surface diffusion, lateral growth, or surface tension, providing a conformal growth. A small $\beta$ value may be also indicating the prevalence of the surface 
diffusion, being previously observed in $\mathrm{Si}_{3} \mathrm{~N}_{4}$ thin films grown by sputtering techniques [31], due to the combination of a very low working pressure with a low deposition rate. Surface diffusion favors a smooth growing surface instead a shadowing effect. Chu et al. [56] have indicated that a small $\beta$ value $(\sim 0.25)$ allows to neglect shadowing, stress and step-edge barrier effects during TiN film growth by sputtering deposition at both low temperature and pressure. Thus, they proposed as roughening mechanism the shot noise effect, whereas the smoothening mechanism was the surface diffusion. However, it is expected a roughness exponent close to 1 for a predominant surface diffusion process, which does not agree with the results of these a- $\mathrm{CH}_{x}$ coatings. Global roughness exponent values, around 1, agree with the surface diffusion model that could be applied at large length scale growth of the a- $\mathrm{CH}_{\mathrm{x}}$ coatings [41]. But only the sample deposited from the mixture with acetylene and hydrogen presents a high $\alpha$ value, where it would be clear an important contribution of surface diffusion, but not enough. As alternative, the evaporation-recondensation process involves a very low $\alpha$ value, although this process is usually weak at room temperature depositions.

The combination of both smoothening mechanisms corresponds to a roughness exponent lower than $1(\sim 2 / 3)$ according to the Mullins diffusion model [41]. This approximation includes a non-linear surface diffusion process, due to the lateral growth, together with a weak evaporation-recondensation at earlier growth times to describe a growth in lowlying, large curvature areas of the surface. At larger growth times, Mullins approximations tends to follow the EW model [56], what seems to agree with the case of the a- $\mathrm{CH}_{\mathrm{x}}$ coating grown from the mixtures with acetylene. Mullins diffusion model predicts a low coarsening exponent of 1/4. Nevertheless, dynamic exponent does not 
present an universal behaviour since depends on the experimental deposition conditions, through an influence on the diffusion strength or the sticking coefficient of the species [41]. Coarsening exponent can be estimated from the evolution of the lateral correlation length with time in a potential relation type $\xi_{\sim} \mathrm{t}^{1 / \mathrm{z}}[41,57]$. Fig. 7 presents different values of the coarsening exponent for the smooth a- $\mathrm{CH}_{x}$ coatings. The use of the $\mathrm{Ar}+\mathrm{C}_{2} \mathrm{H}_{2}$ mixture provides a higher $\mathrm{z}^{-1}$ value of 0.39 , indicating the mound coarsening on the surface [26]. Meanwhile, sample deposited from the $\mathrm{Ar}+\mathrm{H}_{2}$ precursor shown similar values than those previously observed in smooth DLC coatings $(\sim 0.21)$ [27]. In the case of the combination of acetylene and hydrogen for the deposition of a- $\mathrm{CH}_{\mathrm{x}}$ thin films, the coarsening exponent was found significantly low. It could be possible to deduce that the hydrogen flux presented in the reactive mixture reduced the coarsening of the a- $\mathrm{CH}_{x}$ microstructure, i.e. the evolution of the lateral correlation length was delayed.

\subsection{Relation between the main reactive species and the $a-\mathrm{CH}_{x}$ coating growth} mechanisms

As it is proposed in Fig. 8 to summarize the main effects of reactive species during the growth of the a- $\mathrm{CH}_{\mathrm{x}}$ coatings, the prevalence of a Mullins diffusion mechanism suggests that the fragments of precursor reach the surface with certain mobility. Similar scaling exponent at larger deposition time between the a- $\mathrm{CH}_{\mathrm{x}}$ coatings grown from the two mixtures with acetylene suggests that preferential hydrocarbon radicals are arriving to the surface, despite the high additional hydrogen presence, as it is represented in Fig. 8b and $8 \mathrm{c}$. It is possible to assume that the concentration of active species have an influence on the growth rate, while the type of radicals determines the surface microstructure [42]. 
Thus, Fig 8a indicates that hydrogen species may affect the initial independent grains growth, while the development of higher surface aggregates, observed in the other cases, seems to depend on the hydrocarbon radicals, as the scaling exponents have suggested. Therefore, Fig. $8 \mathrm{~b}$ and $8 \mathrm{c}$ present how radicals with a low sticking coefficient, such as $\mathrm{CH}_{2}\left(10^{-2} \sim 10^{-4}\right)$, are involved in a surface diffusion mechanism [21]. Meanwhile, species with higher sticking coefficients close to 1 , such as $\mathrm{CH}$ molecules in Fig. 8 b or $\mathrm{C}$ atoms in Fig. 8a, cause a fast chemisorption mechanism and, subsequently, less surface smoothening. Posterior material coalescence is supported by the common off-normal arrival of particles at the experimental deposition conditions.

According to the fact that a shadowing effect has been associated to a high sticking coefficient, whereas a lower sticking coefficient tends to favour reemission processes, the hydrogen mixture might present a shadowing effect on the $a-\mathrm{CH}_{\mathrm{x}}$ grown surface. However, a shadowing prevalence would increase the roughness, what has not been observed in that sample. Instead of that, hydrogen species can affect the surface morphology through an etching process, suggested in Fig. 8a. In that case, the influence of the sticking coefficient on the film growth is the opposite: higher sticking coefficient is responsible for a strong etching and, subsequently a surface smoothening, mainly on the tops of the surface mounds [41]. Species with lower sticking coefficients may produce an etching mechanism through reemission that allows easily reach the valleys of the surface, improving the roughening, as it is included in Fig. $8 \mathrm{~b}$ for the a- $\mathrm{CH}_{\mathrm{x}}$ deposition with the acetylene precursor. This effect is in agreement with the different roughness obtained for the a- $\mathrm{CH}_{\mathrm{x}}$ coatings deposited from the mixture with hydrogen or acetylene. In any case, it should be noted that the etching influence is generally low at room temperature. For the 
sample deposited from the $\mathrm{Ar}+\mathrm{C}_{2} \mathrm{H}_{2}+\mathrm{H}_{2}$ mixture, growth mechanisms are a combination of the main processes of both depositions with hydrogen and acetylene, represented in Fig. 8c. There must be a competition between shadowing and reemission processes to increase the roughness. As it is well known, an incident atom coming from a sputtering deposition has a high kinetic energy when reaching the surface and a sticking coefficient different from 1. After the surface contact, the corresponding energy loss facilitates the reemission of the atom increasing the sticking probability. This results in a global increase of the surface roughness. Hydrogen atoms might also have an influence in the effective sticking coefficient of the hydrocarbon radicals due to the formation of dangling bonds as preferred chemisorption sites [21], accompanied by the improvement of the roughness.

\section{Conclusion}

Deposition of a- $\mathrm{CH}_{\mathrm{x}}$ coatings by reactive pulsed magnetron sputtering at low pressure has resulted in a high hydrogen incorporation, uniform in-depth chemical composition and smooth surface. From the dynamic scaling approximation, a- $\mathrm{CH}_{\mathrm{x}}$ samples presented the $\alpha, \beta$ and $\mathrm{z}^{-1}$ values of $0.29,0.13$ and 0.39 from the deposition with the $\mathrm{Ar}+\mathrm{C}_{2} \mathrm{H}_{2}$ mixture, being of $0.60,0.13$ and 0.05 for the sample corresponding to the $\mathrm{Ar}+\mathrm{C}_{2} \mathrm{H}_{2}+\mathrm{H}_{2}$ mixture and $0.18,0.21$ and 0.15 with the $\mathrm{Ar}+\mathrm{H}_{2}$ precursor. Growth of the a- $\mathrm{CH}_{\mathrm{x}}$ coatings can be described by the Mullins diffusion model. Hydrogen species seemed to improve the smoothening through a lateral growth in a conformal way supported by etching processes. This favored the generation of a microstructure close to polymeric-like, 
accompanied by a small increase of the bulk density. Meanwhile, the main hydrocarbon radicals promoted the roughening by means of surface diffusion in large curvature regions and the contribution of reemission mechanisms. These hydrocarbon species improved the deposition rate and provided the formation of transpolyacetylene aggregations included in a more $\mathrm{sp}^{2}$ clustering structure of the $\mathrm{a}-\mathrm{CH}_{\mathrm{x}}$ coating.

\section{Acknowledgments}

This work was partially supported by the Belgian Walloon Region, D606, and by the European Commission Programme FP7 REGPOT, AL-NANOFUNC. 


\section{Tables}

Table 1: a- $\mathrm{CH}_{\mathrm{x}}$ nomenclature according to the different flux of reactive gasses and atomic chemical composition of the deposited a-C:H thin films expressed as the carbon (C), oxygen $(\mathrm{O})$ and hydrogen $(\mathrm{H})$ atomic percentages. Thickness, deposition rate and density values are also included. 


\section{List of figure captions}

Fig. 1.- Mass spectra for different experimental deposition conditions of the a-CHx coatings, i.e. the mixture of reactive hydrogen-containing gasses.

Fig. 2.- Concentration in-depth distributions as measured by nuclear reactions of carbon, oxygen and hydrogen on the a- $\mathrm{CH}_{\mathrm{x}}$ thin film deposited from a mixture of $\mathrm{Ar}+\mathrm{C}_{2} \mathrm{H}_{2}$ gasses.

Fig. 3.- Visible Raman spectra of a-CHx $\mathrm{CH}_{\mathrm{x}}$ coatings deposited from the different hydrogencontaining precursors.

Fig. 4- AFM topography images $(1 \mu \mathrm{mx} 1 \mu \mathrm{m})$ of a- $\mathrm{CH}_{\mathrm{x}}$ surfaces deposited from different hydrogen-containing precursors at several growth stages (different thickness). Height scales are indicated in the grey color scales and the roughness is represented as the mean square roughness coefficient $\mathrm{R}_{\mathrm{ms}}$.

Fig. 5.- Dynamic scaling exponents of the a- $\mathrm{CH}_{x}$ coatings in function of the different hydrogen-containing precursors: a) $\beta$ growth exponent deduced from the evolution of the roughness with the deposition time; b) roughness dependence on time according to the Edwards and Wilkinson [41] growth model $\sim(\operatorname{logt})^{0.5}$.

Fig. 6.- Power Density Spectra PSD(k) and Height-Height Correlation Function HCF(L) for the a- $\mathrm{CH}_{\mathrm{x}}$ coatings deposited at different mixtures of hydrogen-containing gasses. 
Fig. 7.- Dynamic scaling exponents of the a- $\mathrm{CH}_{\mathrm{x}}$ coatings in function of the different hydrogen-containing precursors: a) evolution on time of the $\alpha$ roughness exponent, at global (from the $\operatorname{PSD}(\mathrm{k})$ function) and local (from the $\mathrm{HCF}(\mathrm{L})$ function) approximations; b) $\mathrm{z}^{-1}$ coarsening exponent deduced from the evolution of the critical lateral length $\xi$.

Fig. 8.- Diagram proposed for the a- $\mathrm{CH}_{\mathrm{x}}$ coating growth, deposited by magnetron sputtering, when using different precursors: $\mathrm{Ar}+\mathrm{C}_{2} \mathrm{H}_{2}, \mathrm{Ar}+\mathrm{H}_{2}$ and $\mathrm{Ar}+\mathrm{C}_{2} \mathrm{H}_{2}+\mathrm{H}_{2}$ mixtures. Main involved species (with $\mathrm{x}, \mathrm{y}=1,2$ ) and predominant growth mechanisms are indicated in each case. 


\section{REFERENCES}

[1] Robertson J. Diamond-like amorphous carbon. Materials Science \& Engineering R-Reports. 2002 May 24;37(4-6):129-281.

[2] Rybachuk M, Bell JM. Electronic states of trans-polyacetylene, poly(p-phenylene vinylene) and sp-hybridised carbon species in amorphous hydrogenated carbon probed by resonant Raman scattering. Carbon. 2009 Aug;47(10):2481-90.

[3] Piazza F, Grambole D, Zhou L, Talke F, Casiraghi C, Ferrari AC, et al. Large area deposition of hydrogenated amorphous carbon films for optical storage disks. Diamond and Related Materials. 2004 Apr-Aug;13(4-8):1505-10.

[4] Hauert R. A review of modified DLC coatings for biological applications. Diamond and Related Materials. 2003 Mar-Jul;12(3-7):583-9.

[5] Roy RK, Lee KR. Biomedical applications of diamond-like carbon coatings: A review. Journal of Biomedical Materials Research Part B-Applied Biomaterials. 2007 Oct;83B(1):72-84.

[6] Casiraghi C, Piazza F, Ferrari AC, Grambole D, Robertson J. Bonding in hydrogenated diamond-like carbon by Raman spectroscopy. Diamond and Related Materials. 2005 Mar-Jul;14(3-7):1098-102.

[7] Ibenskas A, Galdikas A, Meskinis S, Andrulevicius M, Tamulevicius S. Ion beam deposition of amorphous hydrogenated carbon films on amorphous silicon interlayer: Experiment and simulation. Diamond and Related Materials. 2011 May-Jun;20(5-6):693702.

[8] Eskusson J, Jaaniso R, Lust E. Diamond-like phase formation in an amorphous carbon films prepared by periodic pulsed laser deposition and laser irradiation method. Applied Surface Science. 2009 May 15;255(15):7104-8.

[9] Czyzniewski A. Preparation and characterisation of a-C and a-C:H coatings deposited by pulsed magnetron sputtering. Surface \& Coatings Technology. 2009 Jan 15;203(8):1027-33.

[10] Hang RQ, Ma SL, Chu PK. Corrosion behavior of DLC-coated NiTi alloy in the presence of serum proteins. Diamond and Related Materials. 2010 Oct;19(10):1230-4.

[11] Lousinian S, Logothetidis S, Laskarakis A, Gioti M. Haemocompatibility of amorphous hydrogenated carbon thin films, optical properties and adsorption mechanisms of blood plasma proteins. Biomolecular Engineering. 2007 Feb;24(1):10712.

[12] Keunecke M, Weigel K, Bewilogua K, Cremer R, Fuss HG. Preparation and comparison of a-C:H coatings using reactive sputter techniques. Thin Solid Films. 2009 Dec 31;518(5):1465-9.

[13] Miladinovic SM, De Vriendt V, Robotham SA, Maseri F, Lucas S, Wilkins CL. Laser Desorption/Ionization Fourier Transform Mass Spectrometry of Thin Films Deposited on Silicon by Plasma Polymerization of Acetylene. Journal of the American Society for Mass Spectrometry. 2010 Mar;21(3):411-20.

[14] Chowdhury S, Laugier MT, Rahman IZ. Characterization of DLC coatings deposited by rf magnetron sputtering. Journal of Materials Processing Technology. 2004 Nov 10;153:804-10. 
[15] Caschera D, Cossari P, Federici F, Kaciulis S, Mezzi A, Padeletti G, et al. Influence of PECVD parameters on the properties of diamond-like carbon films. Thin Solid Films. 2011 Apr 1;519(12):4087-91.

[16] Hosseini SI, Shokri B, Firouzjah MA, Kooshki S, Sharifian M. Investigation of the properties of diamond-like carbon thin films deposited by single and dual-mode plasma enhanced chemical vapor deposition. Thin Solid Films. 2011 Mar 1;519(10):3090-4.

[17] Sonderby S, Berthelsen AN, Almtoft KP, Christensen BH, Nielsen LP, Bottiger J. Optimization of the mechanical properties of magnetron sputtered diamond-like carbon coatings. Diamond and Related Materials. 2011 May-Jun;20(5-6):682-6.

[18] Wang YX, Ye YP, Li HX, Ji L, Chen JM, Zhou HD. A magnetron sputtering technique to prepare a-C:H films: Effect of substrate bias. Applied Surface Science. 2011 Jan 1;257(6):1990-5.

[19] Maheswaran R, Ramaswamy S, Thiruvadigal DJ, Gopalakrishnan C. Systematic study of various stages during the growth process of diamond-like carbon film by atomic force microscopy. Journal of Non-Crystalline Solids. 2011 Apr 1;357(7):1710-5.

[20] Logothetidis S, Patsalas P, Gioti M, Galdikas A, Pranevicius L. Growth kinetics of sputtered amorphous carbon thin films: composition studies and phenomenological model. Thin Solid Films. 2000 Nov 1;376(1-2):56-66.

[21] Kim IY, Hong SH, Consoli A, Benedikt J, von Keudell A. Roughness evolution during a-C : $\mathrm{H}$ film growth in methane plasmas. Journal of Applied Physics. 2006 Sep $1 ; 100(5)$.

[22] Acsente T, Ionita ER, Stancu C, Ionita MD, Dinescu G, Grisolia C. OES monitoring of sequential deposition of $\mathrm{C} / \mathrm{W}$ layers by $\mathrm{PECVD} / \mathrm{magnetron}$ sputtering techniques. Surface \& Coatings Technology. 2011 Jul 25;205:S402-S6.

[23] Baby A, Mahony CMO, Maguire PD. Acetylene-argon plasmas measured at a biased substrate electrode for diamond-like carbon deposition: I. Mass spectrometry. Plasma Sources Science \& Technology. 2011 Feb;20(1).

[24] De Vriendt V, Miladinovic SM, Colaux JL, Maseri F, Wilkins CL, Lucas S. Growth Mechanisms Involved in the Synthesis of Smooth and Microtextured Films by Acetylene Magnetron Discharges. Langmuir. 2011 Jul 19;27(14):8913-22.

[25] Baby A, Mahony CMO, Lemoine P, Maguire PD. Acetylene-argon plasmas measured at an rf-biased substrate electrode for diamond-like carbon deposition: II. Ion energy distributions. Plasma Sources Science \& Technology. 2011 Feb;20(1).

[26] Zhang GX, Weeks BL, Holtz M. Application of dynamic scaling to the surface properties of organic thin films: Energetic materials. Surface Science. 2011 Feb;605(34):463-7.

[27] Zhu XD, Naramoto H, Xu Y, Narumi K, Miyashita K. Coarsening dynamics and surface instability during ion-beam-assisted growth of amorphous diamondlike carbon. Physical Review B. 2002 Oct 15;66(16).

[28] Buijnsters JG, Camero M, Vazquez L. Growth dynamics of ultrasmooth hydrogenated amorphous carbon films. Physical Review B. 2006 Oct;74(15).

[29] Pei YT, Chen CQ, Shaha KP, De Flosson JTM, Bradley JW, Voronin SA, et al. Microstructural control of TiC/a-C nanocomposite coatings with pulsed magnetron sputtering. Acta Materialia. 2008 Feb;56(4):696-709. 
[30] Pisana S, Casiraghi C, Ferrari AC, Robertson J. Roughness evolution during growth of hydrogenated tetrahedral amorphous carbon. Diamond and Related Materials. 2006 Apr-Aug;15(4-8):898-903.

[31] Yu LH, Xu JH, Dong SR, Kojima I. Surface morphology and growth mechanisms for sputtered amorphous silicon nitride thin films. Thin Solid Films. 2008 Feb 29;516(8):1781-7.

[32] Moseler M, Gumbsch P, Casiraghi C, Ferrari AC, Robertson J. The ultrasmoothness of diamond-like carbon surfaces. Science. 2005 Sep 2;309(5740):15458.

[33] SF Edwards DW. Proc R Soc Lond, A. 1966;44.

[34] M. Kardar GP, Y. Zhang. Dynamic Scaling of Growing Interfaces. Phys Rev Lett. 1986;56(9):3.

[35] Drotar JT, Zhao YP, Lu TM, Wang GC. Surface roughening in shadowing growth and etching in 2+1 dimensions. Physical Review B. 2000 Jul 15;62(3):2118-25.

[36] Dassarma S, Tamborenea P. A New Universality Class for Kinetic Growth - OneDimensional Molecular-Beam Epitaxy. Physical Review Letters. 1991 Jan 21;66(3):3258.

[37] Colaux JL. <http://wwwfundpacbe/simtarget>. 2009.

[38] M. Mayer iJLD, I.L. Morgan 15th Int Conf on the Application of Accelerators in Research and Industry, American Institute of Physics, University of North Texas (Texas USA)(Eds) 1998.

[39] Horcas I, Fernandez R, Gomez-Rodriguez JM, Colchero J, Gomez-Herrero J, Baro AM. WSXM: A software for scanning probe microscopy and a tool for nanotechnology. Review of Scientific Instruments. 2007 Jan;78(1).

[40] A. L. Barabasi HES. Fractal Concepts in Surface Growth. Cambridge University Press. 1995.

[41] M Pelliccione T-ML. Evolution of Thin Film Morphology. Modeling and Simultions. Springer-Verlag Berlin Heidelberg. 2008.

[42] Yanguas-Gil A, Cotrino J, Walkiewicz-Pietrzykowska A, Gonzalez-Elipe AR. Scaling behavior and mechanism of formation of $\mathrm{SiO} 2$ thin films grown by plasmaenhanced chemical vapor deposition. Physical Review B. 2007 Aug;76(7).

[43] Ulrich S, Theel T, Schwan J, Ehrhardt H. Magnetron-sputtered superhard materials. Surface \& Coatings Technology. 1997 Dec;97(1-3):45-59.

[44] Jr R, John P, Wilson JIB, Fan Y. The role of C(2) in nanocrystalline diamond growth. Journal of Applied Physics. 2004 Dec 1;96(11):6724-32.

[45] Casiraghi C, Ferrari AC, Robertson J. Raman spectroscopy of hydrogenated amorphous carbons. Physical Review B. 2005 Aug;72(8).

[46] Rybachuk M, Bell JM. The observation of $\mathrm{sp}(2)$ fraction disorder using dual wavelength Raman spectroscopy in a-C : $\mathrm{H}$ films fabricated using an open inductively coupled plasma reactor. Diamond and Related Materials. 2006 Apr-Aug;15(4-8):977-81.

[47] Chu PK, Li LH. Characterization of amorphous and nanocrystalline carbon films. Materials Chemistry and Physics. 2006 Apr 10;96(2-3):253-77.

[48] Ferrari AC, Robertson J. Interpretation of Raman spectra of disordered and amorphous carbon. Physical Review B. 2000 May 15;61(20):14095-107. 
[49] Hsu JS, Tzeng SS, Wu YJ. Influence of hydrogen on the mechanical properties and microstructure of DLC films synthesized by r.f.-PECVD. Vacuum. 2008 Oct $15 ; 83(3): 622-4$.

[50] Houska J, Klemberg-Sapieha JE, Martinu L. Formation and behavior of unbonded hydrogen in a-C:H of various compositions and densities. Surface \& Coatings Technology. 2009 Sep 15;203(24):3770-6.

[51] Silva CWME, Branco JRT, Cavaleiro A. How can H content influence the tribological behaviour of W-containing DLC coatings. Solid State Sciences. 2009 Oct:11(10):1778-82.

[52] Casiraghi C. Effect of hydrogen on the UV Raman intensities of diamond-like carbon. Diamond and Related Materials. 2011 Feb;20(2):120-2.

[53] Thornton J. Influence of apparatus geometry and deposition conditions on the structure and topography of thick sputtered coatings. J Vac Sci Technol. 1974;11:5.

[54] Aue J, DeHosson JTM. Influence of atomic force microscope tip-sample interaction on the study of scaling behavior. Applied Physics Letters. 1997 Sep 8;71(10):1347-9.

[55] Lopez JM, Rodriguez MA, Cuerno R. Power spectrum scaling in anomalous kinetic roughening of surfaces. Physica A. 1997 Dec 1;246(3-4):329-47.

[56] Chu K, Liu ZJ, Lu YH, Shen YG. Atomic force microscopy study of growth kinetics: Scaling in TiN-TiB2 nanocomposite films on $\operatorname{Si}\left(\begin{array}{lll}1 & 0 & 0\end{array}\right)$. Applied Surface Science. 2006 Sep 30;252(23):8091-5.

[57] Alvarez R, Palmero A, Prieto-Lopez LO, Yubero F, Cotrino J, de la Cruz W, et al. Morphological evolution of pulsed laser deposited $\mathrm{ZrO}(2)$ thin films. Journal of Applied Physics. 2010 Mar 1;107(5). 
Table 1

\begin{tabular}{|c|c|c|c|c|c|c|c|c|}
\hline $\begin{array}{c}\text { Ar } \\
(\operatorname{sccm})\end{array}$ & $\begin{array}{c}\mathbf{C}_{2} \mathbf{H}_{2} \\
(\mathrm{sccm})\end{array}$ & $\begin{array}{c}\mathrm{H}_{2} \\
(\mathrm{sccm})\end{array}$ & $\begin{array}{c}\mathrm{C} \\
(\%) \\
\pm 4 \%\end{array}$ & $\begin{array}{c}0 \\
(\%) \\
\pm 1 \%\end{array}$ & $\begin{array}{c}\mathbf{H} \\
(\%) \\
+3 \%\end{array}$ & $\begin{array}{c}\text { Thickness } \\
\text { (nm) } \\
\pm 2 \mathrm{~nm}\end{array}$ & $\begin{array}{l}\text { Deposition } \\
\text { rate }(\mathrm{nm} / \mathrm{s}) \\
\pm 0.07 \mathrm{~nm} / \mathrm{s}\end{array}$ & $\begin{array}{c}\text { Density } \\
\left(\mathrm{g} / \mathrm{cm}^{3}\right) \\
\pm 0.3 \mathrm{~g} / \mathrm{cm}^{3}\end{array}$ \\
\hline 20 & 4 & 0 & 58 & 5 & 37 & 356 & 0.12 & 1.13 \\
\hline 20 & 4 & 4 & 58 & 4 & 38 & 330 & 0.11 & 1.14 \\
\hline 20 & 0 & 4 & 64 & 5 & 31 & 43 & 0.02 & 1.61 \\
\hline
\end{tabular}




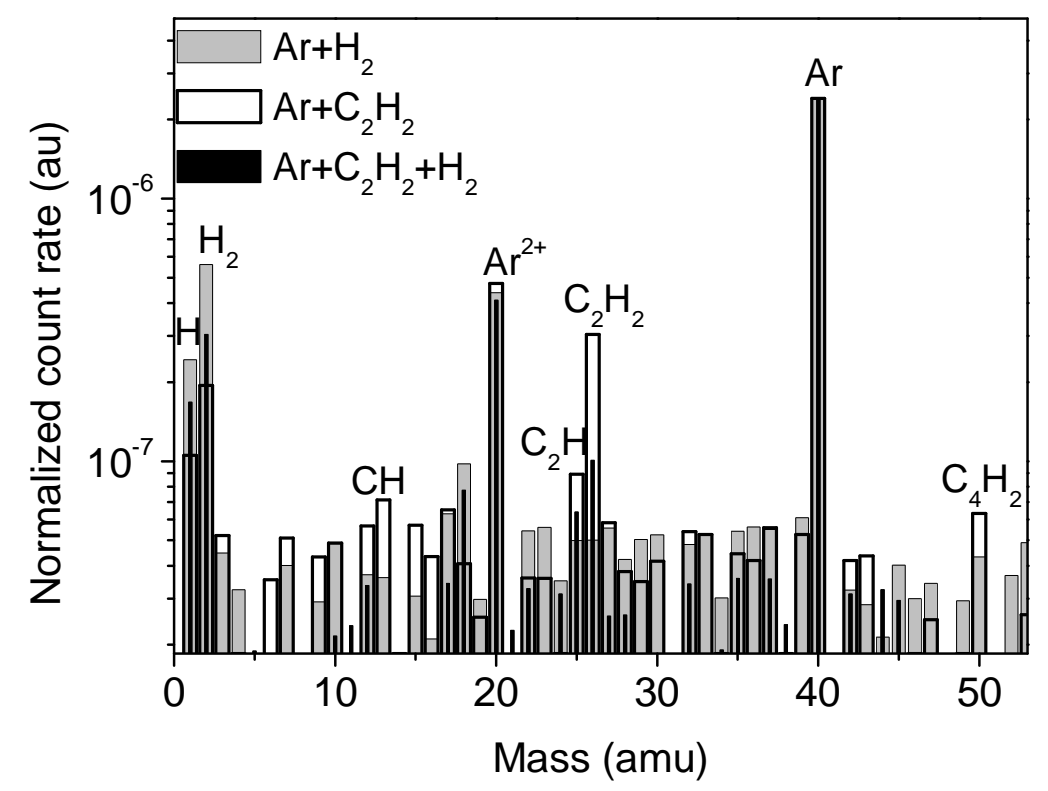

Fig 1

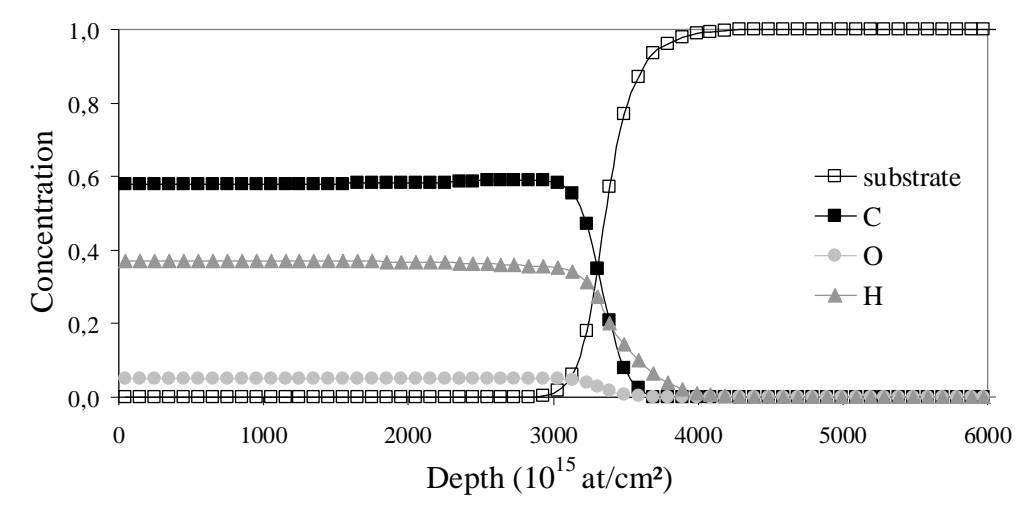

Fig 2 
Fig 3

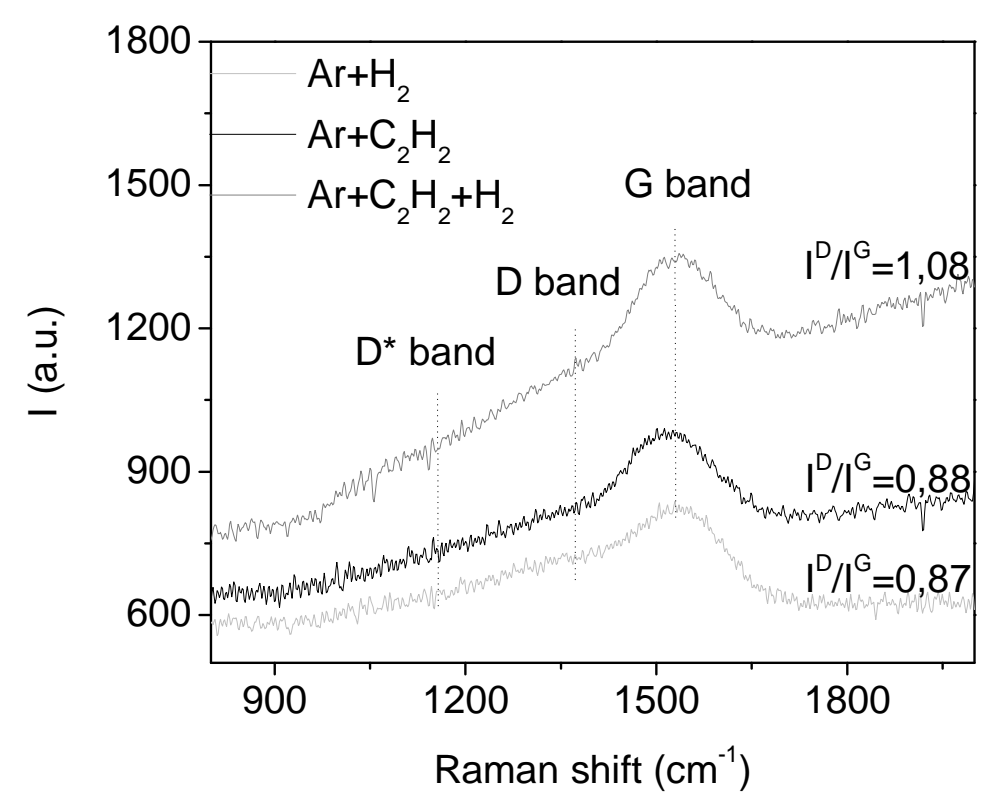




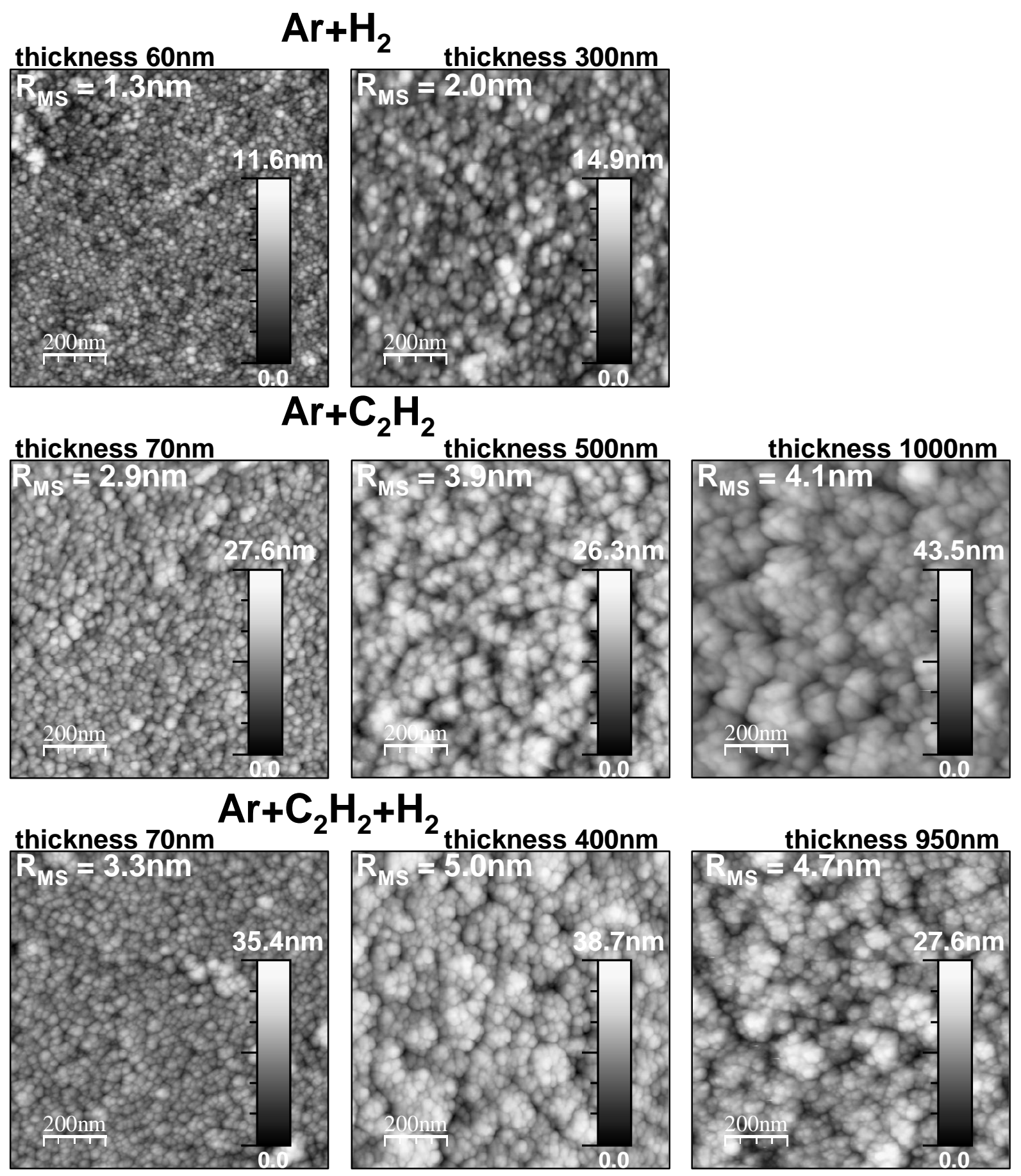

Fig 4 
Fig 5

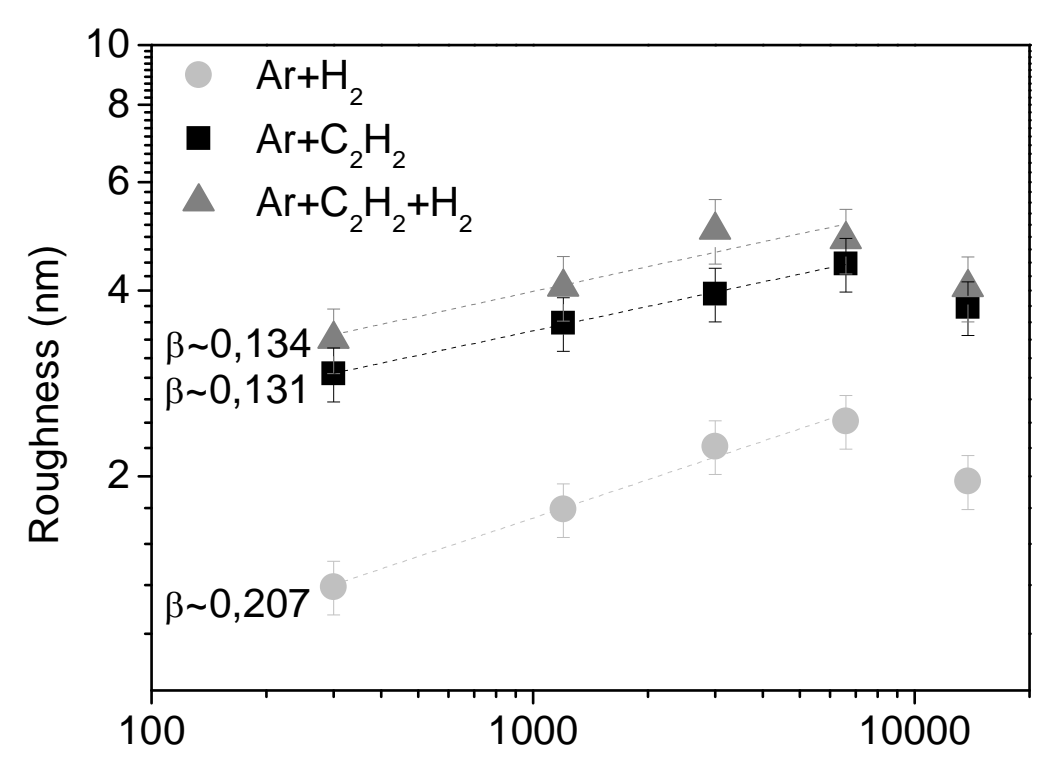

time (s)

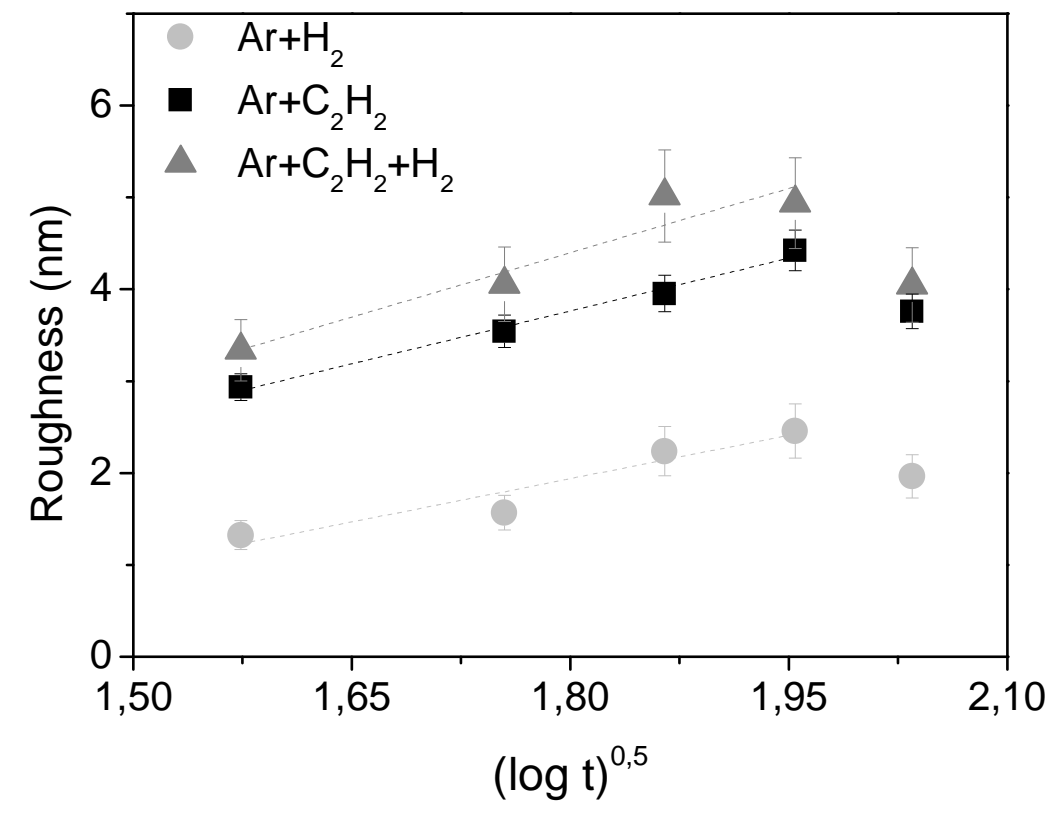

Fig 6
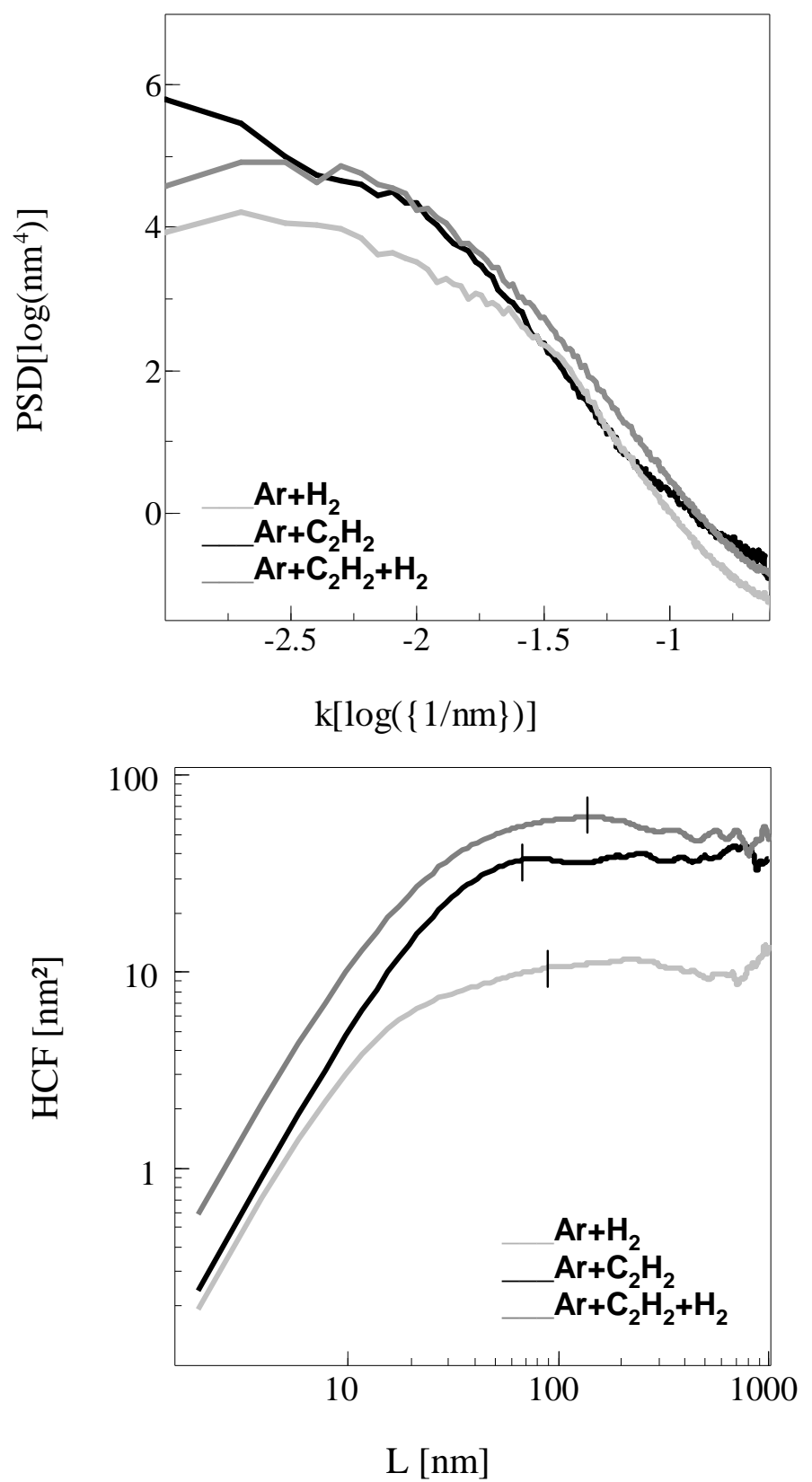
Fig 7
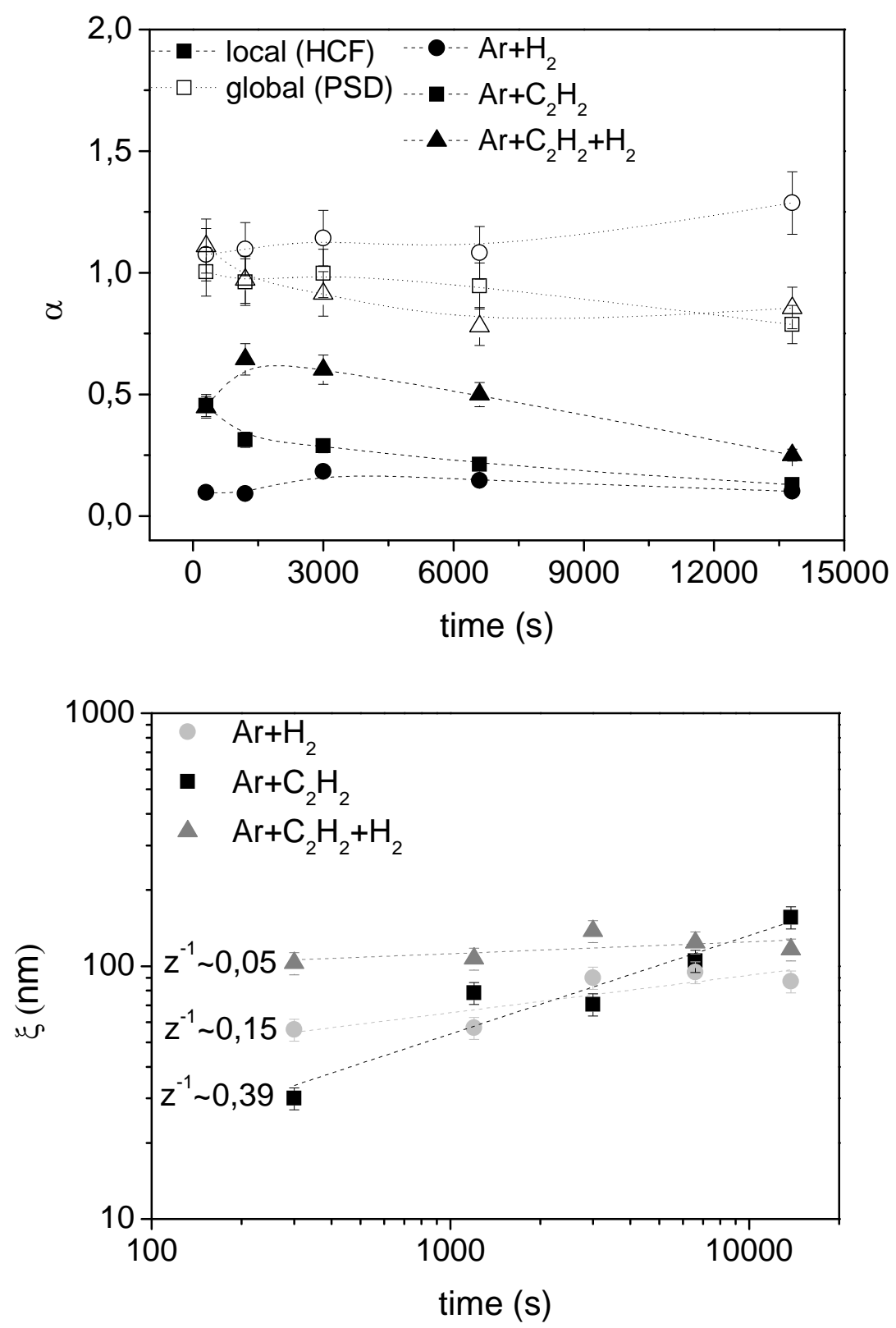


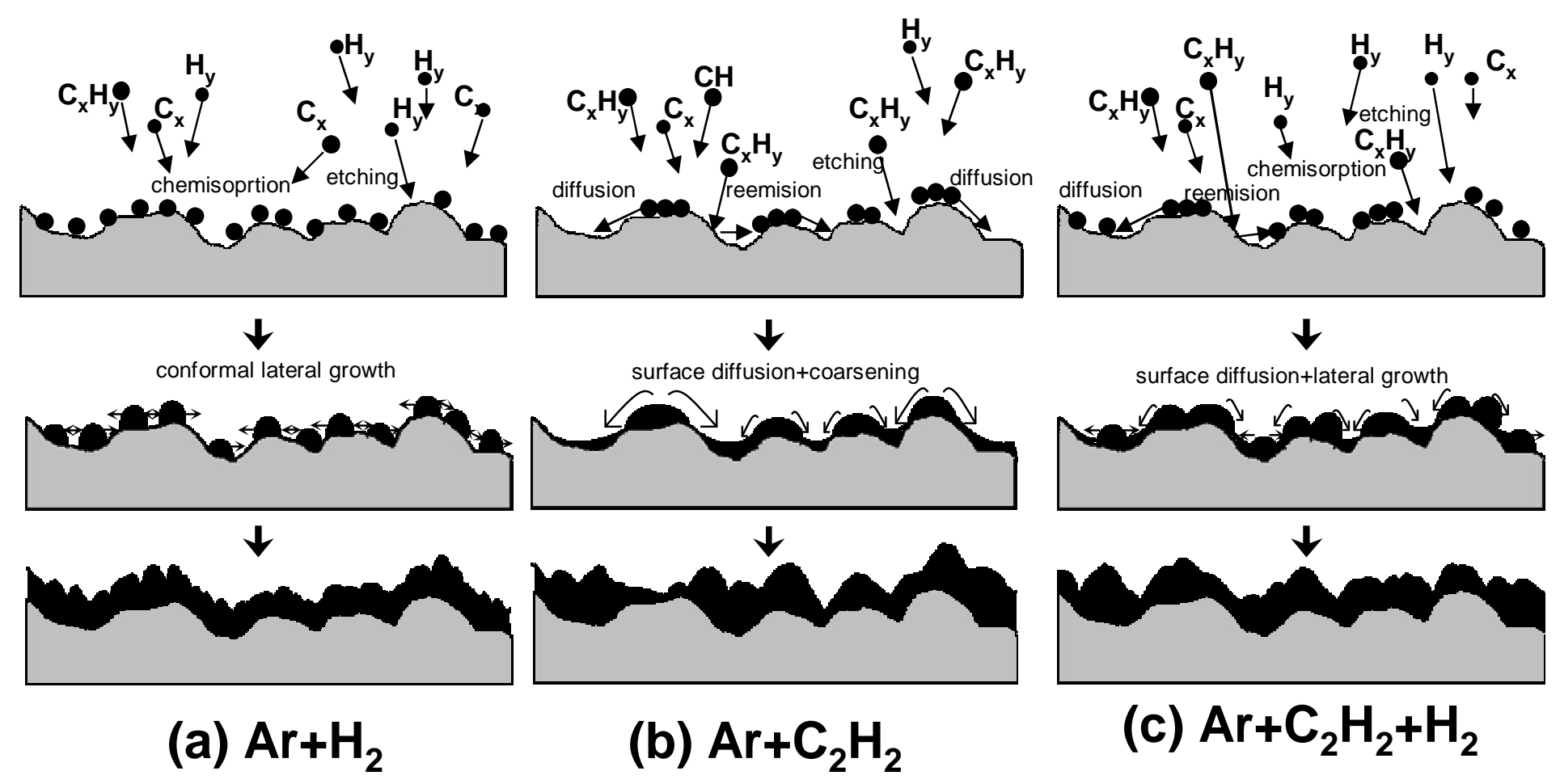

